\title{
Apis florea workers show a prolonged period of nursing behavior
}

\author{
Hemalatha BHAGAVAN $^{1,2}$, Axel BrocKMANN ${ }^{1}$ \\ ${ }^{1}$ National Centre for Biological Sciences, Tata Institute of Fundamental Research, Bangalore, India \\ ${ }^{2}$ Manipal University, Manipal, India
}

Received 11 May 2018 - Revised 9 October 2018 - Accepted 19 November 2018

\begin{abstract}
Studies on behavioral maturation and division of labor in open-nesting honey bee species are scarce as the bee curtain inhibits direct examination of intranidal behaviors. We observed and studied nursing behavior in Apis florea by attaching a foreign comb with open brood to a host colony. Several of the workers that explored the attached comb visited the cells with brood more often and spent more time in cells compared to empty cells. Workers seen inspecting and feeding the brood had well-developed hypopharyngeal glands compared to foragers of their own colony indicating that they are nurses performing nursing behavior. Further, introducing marked 1-day-old workers into the host colony and repeatedly attaching combs with open brood allowed us to estimate the age range of nursing behavior. In our experiments, A. florea workers started to perform significant nursing behavior 8 days after eclosion and continued to show nursing behavior until the age of 28 days, the end of our observation period. Thus, nursing behavior in A. florea appears to be substantially extended relative to A. mellifera .
\end{abstract}

\section{Honey bee / Hypopharyngeal gland / Behavioral maturation / Division of labor}

\section{INTRODUCTION}

Honey bees are one of the major animal models for studying the evolution of sociality and identifying the neural and molecular underpinnings of insect social behavior (Calderone and Page 1988; Farris 2016; Fischman et al. 2011; Robinson et al. 2008; Frumhoff and Baker 1988). However, most of our knowledge about honey bee behavior is based on the studies from Western honey bee, Apis mellifera. Relatively little is known about the individual and social behavior of the Asian honey bee species (Seeley 1985; Seeley 1995; Oldroyd and Wongsiri 2006; Hepburn and Radloff 2011). Consequently, we do not know much about the diversity and

Corresponding author: A. Brockmann,

axel@ncbs.res.in

Manuscript editor: James Nieh evolution of social behavior and age polyethism among honey bee species.

A major evolutionary shift in honey bee behavior likely occurred in parallel to a change in the nesting behavior from open to cavity-nesting (Seeley 1985; Dyer and Seeley 1991). Colonies of open-nesting species build only one comb, and they protect the comb and brood by forming a curtain of bees around it. This bee curtain protects the colony against harmful environmental conditions and predators (Anderson 2002; Dyer and Seeley 1991; Free 1981; Hepburn and Radloff 2011). Workers of open-nesting species are reported to begin foraging at an older age and to live about 2.5 times longer than A. mellifera workers. Dyer and Seely (1991) proposed that the nesting behavior affects the speed of physiological, developmental, and behavioral processes, and that the workers of cavity-nesting species are generally faster than workers of open-nesting species in all these matters. Studying 
open-nesting honey bee species confronts the behavioral researcher with two major challenges. First, these species are wild and bee-keeping procedures which would ease scientific research are not well developed. Second, the comb is protected by the bee curtain, which inhibits examination of intrandial behaviors. Thus, for example, detailed comparative studies on age polyethisms and division of labor among honey bees are still scarce and in their infancy. Until today, studies about age polyethism in open-nesting species (e.g., A. florea and $A$. dorsata ) have been restricted to observations of worker bees upon their appearance on the bee curtain and the crown and onset of foraging (Free 1981; Otis et al. 1990; Dyer and Seeley 1991; Bhagavan et al. 2016), but nothing is known about intranidal behaviors and the progression of age-polyethism. Earlier studies reported that the age at onset of foraging in A. florea is strongly delayed compared to A. mellifera (Seeley and Morse 1976; Dyer and Seeley 1991, Bhagavan et al. 2016). Dyer and Seeley (1991) suggest that the whole process of behavioral maturation might proceed more slowly in opennesting honey bee species compared to cavitynesting honey bees.

A first attempt to identify the molecular underpinnings of behavioral maturation among honey bee species has used 1-day-old workers as substitutes for nurse bees (Sen Sarma et al. 2007). In our report, we desribe experiments in which we studied nursing behavior by attaching a foreign comb to the lower end of the comb of a complete A. florea colony. This allowed us to observe nursing behavior of workers exploring the attached comb. Our findings indicate that $A$. florea perform nursing behavior until the age of 28 days, which is a period much longer than that reported for A. mellifera workers. Thus, the delayed onset of foraging in A. florea workers is accompanied by an extension of nursing period.

\section{MATERIALS AND METHODS}

\subsection{Animals}

A. florea colonies were collected from the campuses of the National Center for Biological Sciences and the University of Agricultural SciencesGKVK, Bangalore. The colonies were mounted in custom-built wooden boxes or attached to low hanging tree branches (Bhagavan et al. 2016)

Combs with open brood were collected after A. florea colonies were smoked and all the adult workers had abandoned the nest. This procedure is commonly used to remove open-nesting species from places where they might cause harm.

The orphaned brood combs were attached to the lower end of the host colonies (Wongvilas et al. 2010; Figure 1). The attachment was completed within $30 \mathrm{~min}$ of removing the bees from the brood colony $(n=5)$. The presence of larva in the brood comb was hypothesized to attract nursing worker bees, allowing the latter to be tracked before the bee curtain was established over the newly attached comb. The behavior was captured in videos recorded using a SONY HDR-CX260 at the rate of $50 \mathrm{fps}$.

\subsection{Visitation of cells with and without larvae}

The colonies were videotaped (50 fps) in order to capture the various within-nest behaviors after the attachment of an orphaned brood comb to the host colony $(n=5)$. From the video, 10 cells with larvae and 10 cells without larvae were arbitrarily selected. These cells were observed for a period of 30 min to count the number of visits by bees and the time each bee spent inside the cells. The analyses were done frame by frame using event logger software BORIS 6.2.3 (Friard and Gamba 2016). As the variances of the data across colonies were not homogenous (time visited: Bartlett's $K$ square $=306.93 \mathrm{df1}, p=0.001$; time spent Bartlett's $K$ square $=427.8 ; p=0.001$ ), we used the Kruskal-Wallis test to compare the number and duration of visits to cells with and without larvae.

\subsection{Identification of nursing workers in A. florea}

Nursing bees were identified using welldescribed features of nursing behavior in A. mellifera . A. mellifera workers generally show either very short visits $(<10 \mathrm{~s})$, which are interpreted as inspecting visits, or long visits ( $>$ $10 \mathrm{~s}$ ), which have been demonstrated to involve the feeding of larvae (Brouwers et al. 1987; 


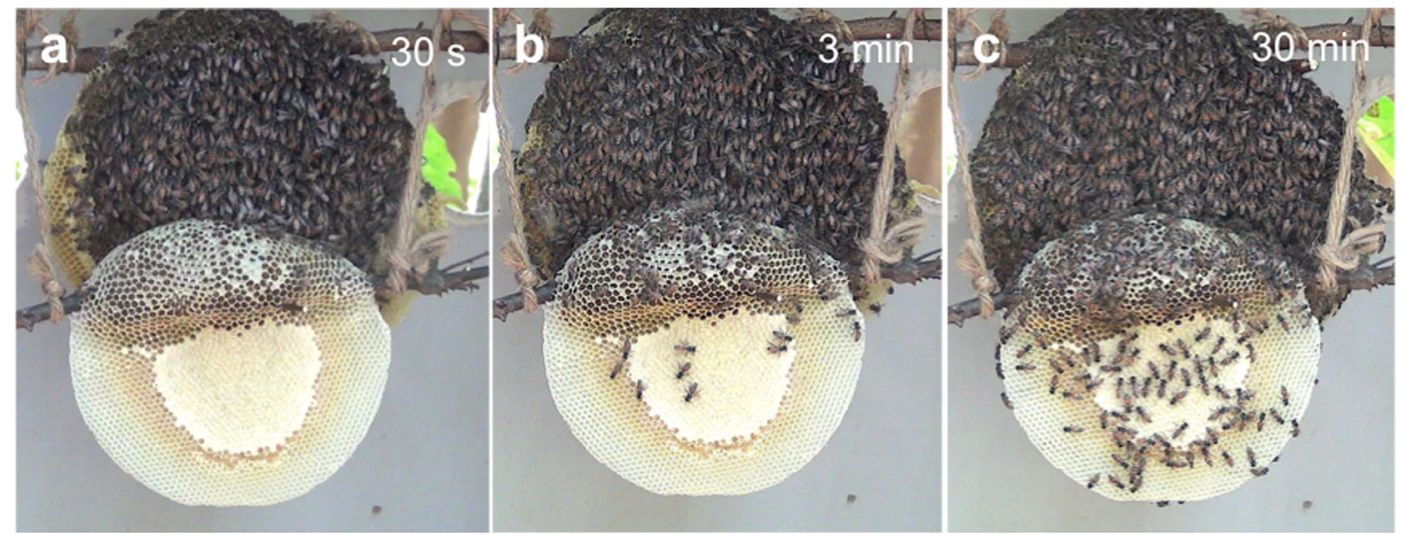

Fig. 1 Time series of photographs documenting the initial phase of bees exploring a newly attached foreign comb. a Freshly attached comb. b Workers from the host colony started to explore the foreign comb within 3 min after attachment. c Within $30 \mathrm{~min}$, the number of bees on the brood comb was increased.

Huang and Otis 1991a, 1991b). In addition, A. mellifera nurses have large and welldeveloped hypopharyngeal glands, which produces food for the brood. The hypopharyngeal glands get reduced when the worker becomes a forager (Winston and Punnett 1982; Brouwers 1982; Smodiš Škerl and Gregorc 2015).

\subsection{Measurement of hypopharyngeal glands}

We measured and compared the size of hypopharyngeal glands (HPG) between workers showing nursing and foraging behavior of the same colony. Nurse bees were collected from the brood area of the attached combs, and foragers were collected from artificial feeders. Nurse bees were identified as those workers that had visited brood cells for longer than $10 \mathrm{~s}$. Shortly after collection, we chilled the bees and opened the head capsule to dissect and take out the HPG (Hrassnigg and Crailsheim 1998). Dissected HPGs were placed in a drop of $0.25 \mathrm{M} \mathrm{NaCl}$ solution on a glass slide. We measured the area of 25 acinii that were arbitrarily selected, to determine the development of the HPGs of the individual worker bees (colony 1: 3 nurse, 3 forager; colony 2: 5 nurse, 5 foragers; and colony 3: 5 nurses, 5 foragers). The area of each acinus was measured using an ocular micrometer (Edmund optics).
To determine the relationship between acinii size and the worker task, we performed a linear mixed-effects analysis using the nlme package in $\mathrm{R}$ (Pinheiro et al. 2018). The dependent variable, acinii size, was modeled as a function of task (fixed effect), colony (random effect), and acini number (as a covariate). We used lme (linear mixed-effect models) function from the nlme package (Pinheiro et al. 2018). Normality and homoscedasticity of the data were confirmed for all models via visual inspection of residual plots.

\subsection{Age range of workers inspecting and feeding brood}

A. florea combs with brood were kept in an incubator at $37^{\circ} \mathrm{C}$, and the workers were collected after they eclosed. These 1-day-old (age 0-24 h) workers were individually paint-marked and then introduced into the foster colony (Bhagavan et al. 2016). The colony was left undisturbed on day 2 so as to not agitate the host colony, as A. florea colonies are prone to absconding when they experience continuous disturbances (Free 1981). Introduced bees were tracked from day 3 onwards by attaching a new brood comb to the host colony. This procedure was repeated every fourth day until the introduced bees reached the age of 28 days. To minimize the disturbance caused by attachment and detachment of the brood combs, 
we left the attached brood comb to the host colony until the next one was attached. We performed three colony replicates. From a total of 194 marked bees, 56 were observed on all experimental days. On each experimental day, the number of bees that appeared on the attached brood comb varied within the colony as well as among the colonies. Thus, we calculated the percentage of bees observed nursing for each single day and then determined the average for the three colonies.

\section{RESULTS}

\subsection{Nurse-like behavior on the attached brood comb}

In all our experiments the host colony accepted the attached brood comb and integrated it into their nest by extending the bee curtain. A first layer of the bee curtain was observed 30 to $80 \mathrm{~min}$ after attaching the brood combs (Figure 1; Table I).

Before the workers of the host colony formed a layer of the bee curtain around the attached comb, we were able to observe workers from the host colony visiting the open brood cells of the comb. Visiting a brood cell included putting only their head or head and thorax into a cell. Observing arbitrarily selected brood cells with or without larvae ( $n=10$ cells per group, 5 colony replicates) over $30 \mathrm{~min}$ yielded information on number and duration of visits by workers. In all colony replicates, we observed workers visiting cells with larvae, and in two of the five replicates we observed workers visiting cells without larvae (Figure 2a). In the two experiments in which workers visited cells without larvae (colony 1 and 3 ), the number of visits and duration of visits were significantly higher for cells with larvae compared to cells without larvae (Kruskal-Wallis; number of visits chi-square = 82.24 , df1, $p=0.001$; duration of visits chisquare $=82.26$, df1, $p=0.001$; Figure 2a, b). Duration of visits to cells without larvae was always shorter than $10 \mathrm{~s}$, whereas cells with larvae were visited for short $(<10 \mathrm{~s})$ as well as long durations ( $>10 \mathrm{~s}$, Figure $2 \mathrm{c}$ ). The longer visits highly likely included feeding of the larvae indicating nursing behavior. These results suggest that the workers visiting brood cells are potential nurse bees.

To address the question as to whether individual workers differed in their activity towards the cells, we arbitrarily selected 15 workers from three colonies ( $\mathrm{C} 1, \mathrm{C} 3$, and $\mathrm{C} 5$, see Figure 2), observed their behavior for as long as possible and measured the duration they spent in each cell on consecutive visits to different cells. Workers visiting the cells with brood differed in the duration they spent in the cells. Sixty percent of the workers showed short $(<10$ s) and long (>10 s) visits, and $40 \%$ of the workers solely performed short visits $(<10 \mathrm{~s}$; Figure 3$)$. Workers that showed longer visits to the cells had significantly larger hypopharyngeal glands (HPG) than the foragers of their own colony $(n=3$, linear mixed-effect models: $t=53.7, p=0.0001$; Figure 4).

\subsection{Age range of workers that show nurse- like behavior}

Over the course of the entire experiment, i.e., from day 3 to day 28, 56 (29\%) out of the total

Table I. Single attachment experiments performed

\begin{tabular}{llll}
\hline Colony & $\begin{array}{c}\text { Host comb size L } \\
(\mathrm{cm}) / \mathrm{W}(\mathrm{cm})\end{array}$ & $\begin{array}{c}\text { Attached comb size } \\
\mathrm{L}(\mathrm{cm}) / \mathrm{W}(\mathrm{cm})\end{array}$ & $\begin{array}{c}\text { Single layer curtain formed on the } \\
\text { attached comb at the brood area }(\mathrm{min})\end{array}$ \\
\hline 1 & $43 / 32$ & $39 / 23$ & 75 \\
2 & $29 / 17$ & $36 / 22$ & 60 \\
3 & $19 / 13$ & $21 / 17$ & 67 \\
4 & $23 / 13$ & $23 / 17$ & 32 \\
5 & $14 / 13$ & $22 / 12$ & 40 \\
\hline
\end{tabular}


of 194 introduced 1-day-old bees appeared on the attached comb and could be observed until the colony established a curtain. Young workers until the age of 8 days did not visit cells with larvae; we only observed them walking, grooming themselves, or just staying stationary (Figure 5). Between the age of 13 and 18 days, the percentage of workers visiting cells with larvae and staying for longer times in the cells started to increase and then remained constant
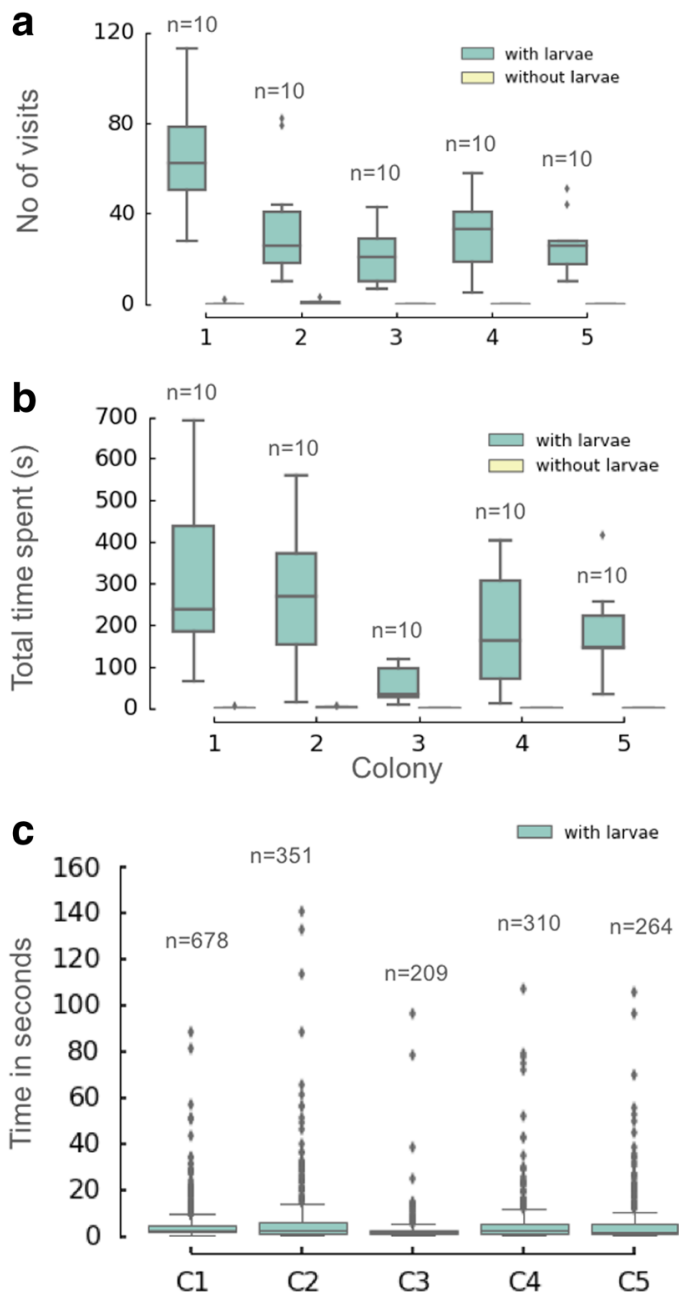

Fig. 2 Number and total time of visits to cells with and without larvae. a Number of visits to cells with $(n=10)$ or without larvae $(n=10)$ for five colonies. b Total time of visits to cells with $(n=10)$ or without larvae ( $n=10$ ) for five colonies. c Mean visit durations for all visits recorded in seconds for all 10 cells with larvae. until the age of 28 days, when we stopped the experiment (Figure 5).

\section{DISCUSSION}

Our study was aimed to determine the age range of nursing behavior in the open-nesting honey bee species, A. florea. Unfortunately, open-nesting species cannot be housed in observation hives, nor is it possible to directly observe intranidal behaviors in a natural colony. We now show that attaching a comb with open brood to the lower end of A. florea colony allows the observation of nursing behavior. We confirmed that the behavior we observed was nursing behavior, showing characteristic aspects of the same known from A. mellifera. First, cells with brood were more often visited by workers of the host colony, and the time duration of the visits were also longer. Among the workers visiting the brood cells, we could distinguish workers that visited the cells only for a short time $(<10 \mathrm{~s})$ and workers that visited the cells for longer durations ( $>10 \mathrm{~s})$. For A. mellifera, visits of brood cells $<10 \mathrm{~s}$ are generally recognized as inspection and visits $>10 \mathrm{~s}$ as feeding. Finally, A. florea workers that visited brood cells for $>10 \mathrm{~s}$ also showed well-developed hypopharyngeal glands compared to foragers of their own colony.

We performed experiments in which we repeatedly attached combs to a colony to study which age groups perform nursing behavior. In our experiments, we observed nursing behavior for workers of the age of 8-28 days. These results provide first evidence that the age span of nursing behavior in A. florea workers is extended compared to that of $A$. mellifera workers. This finding corresponds with earlier reports on a delayed onset of foraging in A. florea workers (Dyer and Seeley 1991; Bhagavan et al. 2016). Studies in A. mellifera indicate that the workers perform nursing behavior from age of 2 days until the age of about 21 days, and then they start foraging (Ribbands 1952; Lindauer 1952; Seeley 1982; Nowogrodzki 1984; Kolmes 1985; Huang et al. 1994; Johnson and Frost 2012). The finding that $A$. florea workers show an extended period of nursing and a delayed onset of 

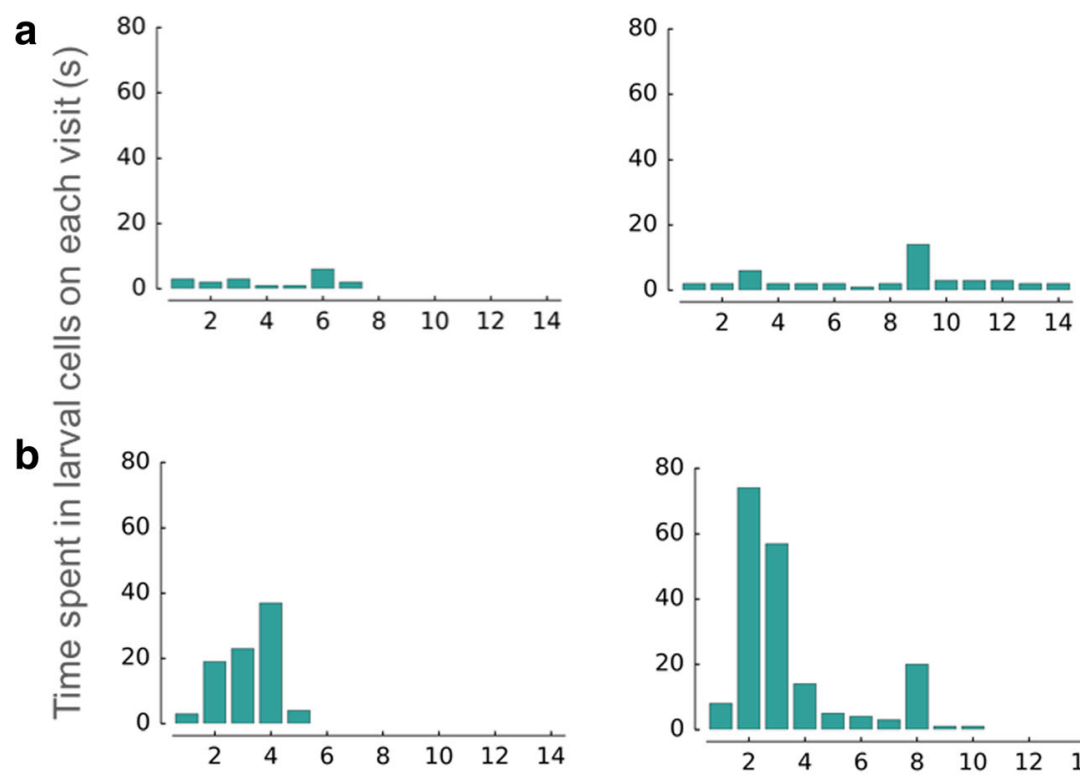

Consecutive cell numbers

Fig. 3 Number and duration of consecutive cell visits by individually identified workers. a Two worker bees that performed only short visits $(<10 \mathrm{~s})$. b Two worker bees that performed short visits $(<10 \mathrm{~s})$ and long visits ( $>10 \mathrm{~s})$.

foraging (Bhagavan et al. 2016) compared to A. mellifera workers suggests that their behavioral maturation proceeds more slowly. Dyer and Seeley (1991) showed that open- and cavity-nesting honey bee species differ in many physiological and behavioral traits that are likely function-related and have something to do with differences in metabolic rate. In brief, workers of cavity-nesting species have an increased metabolic rate which makes them faster than workers of open-nesting species. For example, open-nesting species show a lower frequency of daily foraging trips than do cavity-nesting species. All findings together suggest that the behavioral maturation in A. florea workers is slower compared to A. mellifera workers, or the other way around, behavioral maturation has been accelerated in A. mellifera compared to A. florea (Dyer and Seeley 1991).
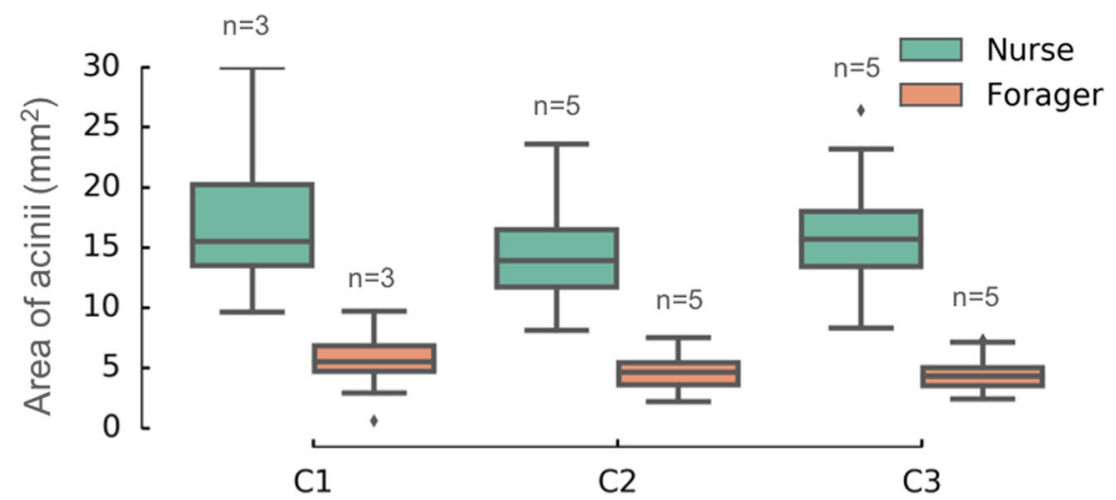

Fig. 4 Comparison of hypopharyngeal gland size of workers feeding the brood and foragers of the same colony. Workers performing visits longer than $10 \mathrm{~s}$ to cells with larvae showed significantly larger acini in their hypopharyngeal gland ( $n=3$ colonies). 


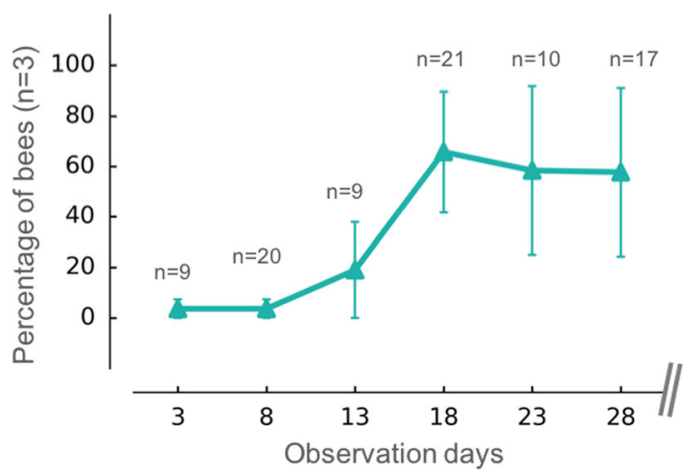

Fig. 5 Age-dependent development of nursing behavior in A. florea workers ( $n=3$ colonies). Green line: percentage of nursing bees visiting cells with larvae ( $n$ above the triangles indicate number of individuals observed).

Exchanging combs with sealed brood between colonies is a common procedure in A. mellifera beekeeping; this technique has been frequently used to study brood rearing behavior and age range of nursing activity in this species (Fukunda and Sakagami 1968; Haydak 1963; Schmickl and Crailsheim 2001; Schmickl et al. 2003). Studies on policing and inter-specific parasitism in A. florea established the procedure of attaching foreign combs next to a host colony (Halling et al. 2001; Wongvilas et al. 2010). In order to study the intranidal behavior, we modified the attachment procedure by attaching the foreign comb to the lower end of the host colonies. In comparison to attaching combs next to the host colony, our method allowed us to observe intranidal behavior for a long period because the curtain formation over the attached brood comb progressed slower (about $55 \mathrm{~min}$ vs $8 \mathrm{~min}$ ). Our finding that $A$. florea workers show a prolonged period of nursing behavior compared to A. mellifera workers hopefully reignites comparative research on behavioral maturation and division of among honey bee species.

\section{ACKNOWLEDGEMENTS}

We would like to thank Hanumantha Raju for finding and collecting A. florea colonies as well as E.A. George help with statistical assistance. P.L. Kohl, S. Unnikrishnan, and A. Young and the reviewers for their helpful suggestions to improve the manuscript.

\section{AUTHORS' CONTRIBUTION}

$\mathrm{HB}$ and $\mathrm{AB}$ designed the study. HB performed and analyzed the experiments. $\mathrm{HB}$ and $\mathrm{AB}$ wrote the manuscript.Funding information

The research was supported by NCBS institutional funds to $\mathrm{AB}$ (12P4167).

\section{COMPLIANCE WITH ETHICAL STANDARDS}

Conflict of interest The authors declare that they have no conflict of interest.

Les ouvrières d'Apis florea ont une durée prolongée de comportement nourricier

Abeille domestique / glande hypopharyngée / maturation comportementale / division du travail

Apis florea Arbeiterinnen haben eine längere Dauer der Ammenbienenphase.

Honigbiene / Hypopharynxdrüse / Alterspolyethismus / Arbeitsteilung

Publisher's note Springer Nature remains neutral with regard to jurisdictional claims in published maps and institutional affiliations.

\section{REFERENCES}

Anderson, C., Theraulaz, G., Deneubourg, J.-L. (2002) Self-assemblages in insect societies. Insectes Soc., https://doi.org/10.1007/s00040-002-8286-y

Bhagavan, H., Muthmann, O., Brockmann, A. (2016) Structural and temporal dynamics of the bee curtain in the open-nesting honey bee species, Apis florea . Apidologie, https://doi.org/10.1007/s13592-0160428-8

Brouwers, E V M. (1982) Measurement of hypopharyngeal gland activity in the honey bee. J. Apic. Res., https://doi.org/10.1080/00218839.1982.11100541

Brouwers, E.V.M., Ebert, R. Beetsma, J., (1987) Behavioural and physiological aspects of nurse bees in relation to the composition of larval food during caste differentiation in the honeybee. J. Apic. Res., https://doi.org/10.1080/00218839.1987.11100729

Calderone, N.W., Page, R.E. (1988) Genotypic variability in age polyethism and task specialization in the honey 
bee, Apis mellifera (Hymenoptera: Apidae). Behav. Ecol. Sociobiol., https://doi.org/10.1007/BF00395694

Dyer, F.C., Seeley, T.D. (1991) Nesting-behavior and the evolution of worker tempo in 4 honeybee species. Ecology 72 (1), 156-170

Farris, S.M. (2016) Insect societies and the social brain. Curr. Opin. Insect Sci., https://doi.org/10.1016/j. cois.2016.01.010

Fischman, B.J., Woodard S.H., Robinson, G E. (2011) Molecular evolutionary analyses of insect societies. PNAS, https://doi.org/10.1073/pnas.1100301108

Free, J. B. (1981) Biology and behaviour of the honey bee Apis florea, and possibilities for beekeeping. Bee World, https://doi.org/10.1080/0005772X.1981.11097817

Friard, O. and Gamba, M. (2016), BORIS: a free, versatile open-source event-logging software for video/audio coding and live observations. Methods Ecol Evol., 7 : 1325-1330

Frumhoff, P.C., Baker, J. (1988) A genetic component to division of labour within honey bee colonies. Nature, https://doi.org/10.1038/333358a0

Fukunda, H., Sakagami, S.F. (1968) Worker brood survival in honeybees. Res. Pop. Ecol. 10 : 31-39

Halling, L.A., B.P. Oldroyd, W. Wattanachaiyingcharoen, A.B. Barron, P. Nanork, S. Wongsiri(2001) Worker policing in the bee Apis florea. Behav. Ecol. Sociobiol. 49: 509-513

Haydak, M.H., (1963) Age of Nurse Bees and Brood Rearing. J. Apic. Res., https://doi.org/10.1080 /00218839.1963.11100067

Hepburn, H. R., Radloff, S.E. (2011) Honeybees of Asia. Springer-Verlag, Berlin Heidelberg

Hrassnigg, N., Crailsheim, K. (1998) Adaptation of hypopharyngeal gland development to the brood status of honeybee (Apis mellifera L. ) colonies. J. Insect Physiol. 44 (10), 929-939

Huang, Z.Y., Otis, G.W. (1991a) Nonrandom visitation of brood cells by worker honey bees (Hymenoptera: Apidae). J. Insect Behav. 4 (2), 177-184

Huang, Z.Y., Otis, G.W. (1991b) Inspection and feeding of larvae by worker honey bees (Hymenoptera, Apidae) - effect of starvation and food quantity. J. Insect Behav. 4 (3), 305-317

Huang, Z.Y., Robinson, G E., Borst, D. W. (1994) Physiological correlates of division of labor among similarly aged honey bees. J. Comp. Physiol., https://doi. org/10.1007/BF00192722

Johnson, B.R., Frost, E. (2012) Individual level patterns of division of labor in honey bees highlight flexibility in colony-level developmental mechanisms. Behav. Ecol. Sociobiol., https://doi.org/10.1007/s00265-012-1341-4

Kolmes, SA. (1985) A quantitative study of the division of labor among worker honey bees. Z. Tierpsychol. 68 (4), 287-302

Lindauer, M. (1952) Ein Beitrag zur Frage der Arbeitsteilung im Bienenstaat. Z. Vergl. Physiol. S. 299-345.
Nowogrodzki, R. (1984) Division of labour in the honey bee colony: A review, Bee World, https://doi. org/10.1080/0005772X.1984.11098788

Oldroyd B.P., Wongsiri S. (2006) Asian Honey Bees: Biology, Conservation, and Human Interactions. Harvard University Press, Boston Mass

Otis, G.W., Mardan, M., McGee, K. (1990) Age polytheism in Apis dorsata. In social insects and the environment. Proc. of the 11th Congress of IUSSI. Bangalore, pp. 378

Pinheiro, J., Bates, D., DebRoy, S., Sarkar, D., and R Core Team (2018). nlme: Linear and Nonlinear Mixed Effects Models. R package version 3.1-137, https:/www. CRAN.R-project.org/package $=$ nlme

Ribbands, C.R. (1952) Division of labour in the honeybee community. Proc. R. Soc. B., https://doi.org/10.1098 /rspb.1952.0041

Robinson G. E., Fernald R. D, Clayton D.F. (2008) Genes and social behavior. Science, https://doi.org/10.1126 /science.1159277

Schmickl, T., Crailsheim, K. (2001) Inner nest homeostasis in a changing environment with special emphasis on honey bee brood nursing and pollen supply. Apidologie https://doi.org/10.1051/apido:2004019

Schmickl, T., Blaschon, B., Gurmann, B., Crailsheim, K. (2003) Collective and individual nursing investment in the queen and in young and old honeybee larvae during foraging and non-foraging periods. Insect. Soc. 50, 174-184

Seeley, T.D. (1982) Adaptive significance of the age polyethism schedule in honey bee colonies. Behav. Ecol. Sociobiol, https://doi.org/10.1007/BF00299306

Seeley, T.D. (1985) Honey bee ecology. A study of adaptation in social life. Princeton University Press; USA. ISBN 0-691-08391. pp 31-36

Seeley, T.. (1995) The wisdom of the hive: the social physiology of honey bee colonies Harvard University Press. 1996

Seeley, T.D., Morse, R.A. (1976) The nest of honey bee (Apis mellifera L.) Insectes Soc., https://doi. org/10.1007/BF02223477

Sen Sarma, M., Whitfield, C.W., Robinson, G.E. (2007) Species differences in brain gene expression profiles associated with adult behavioral maturation in honey bees. BMC Genomics, https://doi.org/10.1186/14712164-8-202

Smodiš Škerl, Maja I., Gregorc, A. (2015) Characteristics of hypopharyngeal glands in honey bees (Apis Mellifera Carnica) from a nurse colony. Slov. Vet. Res. 52 (2), 67-74

Winston, Mark L., and Elizabeth Neilson Punnett. (1982) Factors determining temporal division of labor in honeybees. Can. J. Zool., https://doi.org/10.1139/z82-372

Wongvilas, S., J.S. Higgs, M. Beekman, W. Wattanachaiyingcharoen, S. Deowanish et al., 2010 Lack of inter-specific parasitism between the dwarf honeybees Apis andreniformis and Apis florea. Behavioral Ecology and Sociobiology 64:1165-1170. 